\title{
Economic value of treating lumbar disc herniation in Brazil
}

\author{
Asdrubal Falavigna, MD, PhD, ${ }^{1}$ Nicolas Scheverin, MD, ${ }^{2}$ Orlando Righesso, MD, PhD, ${ }^{1}$ \\ Alisson R. Teles, MD, ${ }^{1}$ Maria Carolina Gullo, PhD, ${ }^{3}$ Joseph S. Cheng, MD, ${ }^{4}$ and K. Daniel Riew, MD ${ }^{5}$ \\ 1Department of Neurosurgery, Laboratory of Clinical Studies and Basic Models of Spinal Disorders, and ${ }^{3}$ Accountancy and \\ Economic Sciences Center, University of Caxias do Sul, Caxias do Sul, Rio Grande do Sul, Brazil; '2Department of Orthopaedics, \\ Hospital Dr. Diego E. Thompson, Buenos Aires, Argentina; ${ }^{D}$ Department of Neurosurgery, Vanderbilt University School of \\ Medicine, Nashville, Tennessee; ${ }^{5}$ Department of Neurological Surgery, Washington University School of Medicine, Saint Louis, \\ Missouri
}

OBJECT Lumbar discectomy is one of the most common surgical spine procedures. In order to understand the value of this surgical care, it is important to understand the costs to the health care system and patient for good results. The objective of this study was to evaluate for the first time the cost-effectiveness of spine surgery in Latin America for lumbar discectomy in terms of cost per quality-adjusted life year (QALY) gained for patients in Brazil.

METHODS The authors performed a prospective cohort study involving 143 consecutive patients who underwent open discectomy for lumbar disc herniation (LDH). Patient-reported outcomes were assessed utilizing the SF-6D, which is derived from a 12-month variation of the SF-36. Direct medical costs included medical reimbursement, costs of hospital care, and overall resource consumption. Disability losses were considered indirect costs. A 4-year horizon with 3\% discounting was applied to health-utilities estimates. Sensitivity analysis was performed by varying utility gain by $20 \%$. The costs were expressed in Reais (R\$) and US dollars (\$), applying an exchange rate of 2.4:1 (the rate at the time of manuscript preparation).

RESULTS The direct and indirect costs of open lumbar discectomy were estimated at an average of $R \$ 3426.72$ $(\$ 1427.80)$ and $R \$ 2027.67$ (\$844.86), respectively. The mean total cost of treatment was estimated at $R \$ 5454.40$ (\$2272.66) (SD R \$2709.17 [\$1128.82]). The SF-6D utility gain was $0.044(95 \% \mathrm{Cl} 0.03197-0.05923, \mathrm{p}=0.017)$ at 12 months. The 4-year discounted QALY gain was 0.176928 . The estimated cost-utility ratio was $\mathrm{R} \$ 30,828.35(\$ 12,845.14)$ per QALY gained. The sensitivity analysis showed a range of $R \$ 25,690.29(\$ 10,714.28)$ to $R \$ 38,535.44(\$ 16,056.43)$ per QALY gained.

CONCLUSIONS The use of open lumbar discectomy to treat LDH is associated with a significant improvement in patient outcomes as measured by the SF-6D. Open lumbar discectomy performed in the Brazilian supplementary health care system provides a cost-utility ratio of $\mathrm{R} \$ 30,828.35(\$ 12,845.14)$ per $\mathrm{QALY}$. The value of acceptable cost-effectiveness will vary by country and region.

http://thejns.org/doi/abs/10.3171/2015.7.SPINE15441

KEY WORDS lumbar disc herniation; health care economics; costs; spine surgery; Brazil

$\mathrm{L}$ UMBAR disc herniation (LDH) is the most common cause of sciatica. The prevalence of symptomatic lumbar radiculopathy is 9.8 per 1000 people $(1 \%) .{ }^{43}$ Although the natural course and outcome of conservative treatment are favorable for the majority of patients, around $20 \%$ of cases are refractory. In those cases surgery is a good option, since the success rates are greater than $80 \% \%^{6,17,34}$ and outcomes are better than conservative treat- ment. ${ }^{30,44,52}$ Due to the high prevalence of lumbar radiculopathy in the general population, surgery for LDH is one of the most common surgical procedures performed in neurosurgical and orthopedics services.

Spinal disorders have a major impact on society in terms of total health care expenditure, work absenteeism, and disability. In the US, for example, the estimated annual costs of lumbar disorders doubled from $\$ 52$ to $\$ 102$

ABBREVIATIONS GDP = gross domestic product; HADS = Hospital Anxiety and Depression Scale; LDH = lumbar disc herniation; ODI = Oswestry Disability Index; QALY = quality-adjusted life year; SPORT = Spine Patient Outcomes Research Trial; SUS = Sistema Único de Saúde; WHO = World Health Organization.

SUBMITTED April 13, 2015. ACCEPTED July 16, 2015.

INCLUDE WHEN CITING Published online December 11, 2015; DOI: 10.3171/2015.7.SPINE15441. 
billion between 1997 and 2005. ${ }^{31}$ As a result of the rising economic costs and finite financial resources, there is an increasing demand to improve the efficiency and value of health care and to provide economic assessments of its value. ${ }^{27}$

Four main types of analyses are currently used in health care economics: cost-minimization, cost-benefit, cost-effectiveness, and cost-utility. ${ }^{35}$ Cost-minimization studies simply describe the costs of treatments for an indication to determine the least expensive. Cost-benefit analyses establish the ratio between resources spent and benefits gained with a determined treatment. Cost-effectiveness studies estimate the value of an intervention by calculating the ratio between the benefit provided by a specific health care intervention and the cost of a specific health outcomes measure. Cost-effectiveness analyses allow for a complete health-economic assessment, with the effects expressed in clinical epidemiology units. Finally, cost-utility is a specific type of cost-effectiveness analysis in which the benefit is expressed as a utility measure, that is, a preference-based measure of health-related quality; it is scored numerically-for example, using a range from 0 to 1 , where 0 represents death and 1 represents perfect health. The utility measure can be used to calculate quality-adjusted life years (QALYs). This model of economical evaluation, based on the preference-based utility measures, provides data that allow for comparison across various disciplines of medicine. Thus, it is the type of economic analysis that is likely to be used to guide payers and policy makers in making coverage decisions. Due the high prevalence of spinal disorders, economic analysis is highly important, but there is a lack of these types of studies in the literature. ${ }^{26}$ Many authors have noted that there are very few studies focused on the health economics of our most common spinal procedures, such as lumbar discectomy. ${ }^{25,29,39,47}$

Health economic evaluations have variations based on region and country, due to their distinct economic environments. These assessments have been used much more extensively in developed countries than in developing nations, and many factors preclude their generalizability and potential transferability from one setting to another. Just as in developed countries such as the US, economic evaluations are also essential in Brazil, where health care resources are often distributed without adequate rationale and many hospitals are underfunded. Moreover, economic cost-utility assessments pertaining to health are still inadequately used in Brazil and other countries of Latin America. To the best of our knowledge, no Brazilian study has been published regarding spine health economics to date. The objective of this study was to determine the costutility ratio of lumbar discectomy in Brazil.

\section{Methods \\ Study Design and Sample}

This study is part of an ongoing large spine outcomes research study conducted in southern Brazil. ${ }^{21}$ From a prospectively collected database, we selected a cohort of 143 consecutive patients with LDH associated with neurological impairment and sciatica who underwent open discectomy. The inclusion criteria were the presence of
LDH on MRI with associated clinical correlation, symptoms refractory to 4 to 8 weeks of conservative treatment or the presence of a progressive motor impairment, and willingness and capacity to participate in the study with follow-up. The exclusion criteria were lack of concordance between the symptoms and lumbar MRI, previous lumbar spine surgery, any preexisting spinal pathology, and lumbar instability. This study was approved by the institutional review board of University of Caxias do Sul.

All patients were evaluated preoperatively, perioperatively, and then at 1,6, and 12 months postoperatively with patient-reported outcome metrics and the neurological findings.

\section{Surgical Technique}

All patients underwent a standard open discectomy via a subperiosteal approach performed by the same surgical team (A.F., O.R.) using a $2.5 \times$ magnification loupe, a frontal light source, and a self-retaining retractor. The preferred nerve decompression technique was sequestrectomy of the extruded disc and foraminotomy. The patients were discharged from the hospital after meeting discharge fitness criteria, including adequate postoperative pain control, mobilization from the bed, and walking.

\section{Patient-Reported Outcome Measures and QALYs}

Data were collected to assess pain, disability, and overall health state from the preoperative time point to 1 year after surgery by using patient-reported outcome questionnaires. To prevent bias, an independent investigator who was not involved with the patient's clinical care administered the questionnaires. Pain intensity was assessed with a numeric rating scale. Disability was measured using the Oswestry Disability Index (ODI) ${ }^{18,19}$ validated for the Brazilian Portuguese language by Vigatto et al. ${ }^{50}$ The SF-36 was used to evaluate health care-related quality of life..$^{51}$ The SF-36 instrument was translated and validated for Brazilian Portuguese in 1999 by Ciconelli et al. ${ }^{12}$ Depression and anxiety were assessed using the Hospital Anxiety and Depression Scale (HADS), ${ }^{8,22}$

At the last evaluation, the patients were asked about their satisfaction with the procedure: "Would you have the same treatment to achieve the same result again?" Patients who answered "definitely yes" or "probably yes" were considered satisfied with the procedure. Dissatisfaction was noted if they answered "do not know," "probably would not," or "definitely would not."

The SF-6D, derived from the SF-36 using a Brazilian weighting system, ${ }^{13}$ was used for utility measurement. ${ }^{10,24}$ The exchange rate used from the Brazilian real to the US dollar was 2.4:1 based on the current data at time of manuscript preparation.

\section{Resource Utilization and Cost}

All cost estimates were based on the charges for patients' hospital records, physician reimbursement, and resource utilization after discharge. Reoperations, low-back pain-related outpatient visits, diagnostic tests, injections, emergency room visits, back-specific medications, and physical therapy days were assessed. The direct medi- 
cal costs comprised institutional, physician, and medical supply utilization. The indirect costs were estimated by assessing the productivity losses because of spine-related problems, such as missed workdays for those employed outside the home based on the average gross wage in the city of Caxias do Sul (based on data from the Ministry of Labor and Employment of the Federal Government), according to the profession of each patient. According to federal legislation, a worker may be absent for illness up to 15 days and have his salary paid by the company. After the 16th day, sick leave is to be paid by the National Social Security Institute system, and the employer has no obligation to pay the worker until he or she returns to his or her original job function. Thus, the calculations of indirect costs include how much companies paid in sick leave as well as the government payments for those unable to work due to their spinal disorders.

\section{Cost Per QALY Gained}

We used the QALYs obtained at the 1-year follow-up after surgery and compared them with the historical results of discectomy in LDH published in the literature. The mean total (direct and indirect) 1-year cost was then calculated in QALYs. The cost per QALY gained by discectomy was the primary end point of this study.

\section{Statistical Analyses}

Estimations were made using a 12-month variation of the SF-6D. To determine the number of QALYs gained by lumbar discectomy, a 4-year horizon with 3\% discounting was applied to health utilities, ${ }^{4}$ taking into account the benefit of surgery for this time period ${ }^{48}$ A QALY provides an estimate of the number of years of improved quality of life a patient can expect to gain from treatment. Dividing the mean cost of treatment by the mean number of QALYs gained provides an estimate of cost utility, noted in cost per QALY. For example, if the patient's health state was 0.5 before treatment and 0.7 after treatment, the annual gain is 0.2 QALYs. A sensitivity analysis was performed by varying the utility measures values by $20 \%$. The costs were expressed in Reais (R\$) and US dollars (\$), using an exchange rate of 2.4:1. All data analysis was generated using SPSS 20.0. The paired Student t-test was used to evaluate the change in scores from the preoperative assessment to the 1-year follow-up assessment.

\section{Results}

Table 1 provides a summary of the demographic and clinical characteristics of the 143 consecutive patients with LDH associated with neurological impairment and sciatica who underwent open discectomy. Intraoperative incidental durotomy occurred in 4 patients $(2.8 \%)$. Postoperative complications occurred in 9 patients (6.3\%): recurrent disc herniation $(n=4,2.8 \%)$, motor deficit $(n=1)$ seroma $(\mathrm{n}=2)$, suture granuloma $(\mathrm{n}=1)$, trochanteric bursitis ( $=1$ ). Of the 4 patients with recurrent disc herniations, 2 were successfully treated with oral analgesics, 1 patient improved with spinal injection, and 1 patient underwent revision surgery. No patient with an incidental durotomy needed revision surgery for cerebrospinal fluid leakage.
TABLE 1. Summary of demographic and clinical characteristics of the patient sample

\begin{tabular}{ll}
\hline \multicolumn{1}{c}{ Characteristic } & \multicolumn{1}{c}{ Value } \\
\hline No. of patients & 143 \\
\hline Female sex & $75(52.4 \%)$ \\
\hline Mean age in yrs (SD) & $46.07(12.50)$ \\
\hline Treated level & $4(2.8 \%)$ \\
\hline L2-3 & $15(10.5 \%)$ \\
\hline L3-4 & $56(39.2 \%)$ \\
\hline L4-5 & $68(47.6 \%)$ \\
\hline L5-S1 & $79.40(30-90)$ \\
\hline Mean duration of symptoms in days (IQR) & $23.74(12-24)$ \\
\hline Duration of hospitalization in hrs (IQR) & $53.73(18.97)$ \\
\hline Duration of surgery in mins (SD) & $28.77(10-30)$ \\
\hline Time to return to work in days (IQR)
\end{tabular}

$\mathrm{IQR}=$ interquartile range.

Lumbar discectomy was shown to reduce pain, disability, and depression and anxiety scores and overall improve the quality of life of patients with LDH refractory to medical treatment at 1-year follow-up. Table 2 demonstrates the change in scores. Satisfaction with treatment was observed in $86.7 \%$ of patients. The SF-6D utility gain was $0.044(95 \%$ CI $0.03197-0.05923, \mathrm{p}=0.017)$ at 1 year. Patients experienced a mean discounted gain of 0.176928 QALYs over the 4-year period.

Table 3 demonstrates the mean costs of treatment. Direct and indirect costs of open discectomy were estimated at an average of $\mathrm{R} \$ 3426.72$ (\$1427.80) and $\mathrm{R} \$ 2027.67$ (\$844.86), respectively. The mean total cost of treatment was estimated at R\$5454.40 (\$2272.66) with a standard deviation of $\mathrm{R} \$ 2709.17$ (\$1128.82) and a range of $\mathrm{R} \$ 2860.22$ (\$1191.75) to $\mathrm{R} \$ 17,311.20$ ( $\$ 7213.00$ ). This range was related to indirect costs and was largely due to the heterogeneity of the patients' professions and lost productivity costs.

The estimated cost-utility ratio was $\mathrm{R} \$ 30,828.35$ $(\$ 12,845.14)$ per QALY gained. The sensitivity analysis showed a range of $\mathrm{R} \$ 25,690.29$ (\$10,714.28) to $\mathrm{R} \$ 38,535.44$ $(\$ 16,056.43)$ per QALY gained.

\section{Discussion}

This study evaluated the cost-utility of lumbar discectomy in patients with LDH refractory to medical treatment in Brazil. The strengths of our study are the use of prospectively accrued data, a validated outcome measure, and a thorough analysis of medical costs. Given the economic and social impact of spinal disorders as well as the difficulty in generalizing and transferring economical analyses from one country to another, especially in comparing developed to developing countries, our findings represent an important step in this type of analysis of spine care in Brazil.

Cost-utility analysis is a subtype of cost-effectiveness analysis. In this analysis, the costs are expressed in monetary units, and the outcomes are utility adjusted. The utility refers to a patient's preference for a particular health outcome. The outcome is expressed in QALYs, where the 
TABLE 2. Changes in health-related quality of life measures after lumbar discectomy

\begin{tabular}{|c|c|c|c|c|}
\hline \multirow[b]{2}{*}{ Outcome Measure } & \multicolumn{2}{|c|}{ Mean Score (SD) } & \multirow[b]{2}{*}{ Mean Change } & \multirow[b]{2}{*}{$\mathrm{p}$ Value } \\
\hline & Baseline & $1 \mathrm{Yr}$ & & \\
\hline ODI & $47.36(21.64)$ & $18.95(15.08)$ & $-28.41(23.18)$ & $<0.0001$ \\
\hline NRS score for pain & $8.69(1.43)$ & $1.13(1.63)$ & $-7.55(2.09)$ & $<0.0001$ \\
\hline HADS & $14.40(6.76)$ & 11.07 (5.69) & $-3.33(5.96)$ & $<0.0001$ \\
\hline \multicolumn{5}{|l|}{ SF-36 } \\
\hline PCS & $32.17(6.65)$ & $41.84(9.77)$ & $9.67(11.41)$ & $<0.0001$ \\
\hline MCS & $41.85(14.39)$ & $48.30(14.38)$ & $6.45(14.95)$ & $<0.0001$ \\
\hline SF-6D & $0.69(0.043)$ & $0.73(0.051)$ & $0.044(0.057)$ & $<0.0001$ \\
\hline
\end{tabular}

MCS = Mental Component Summary; NRS = numeric rating scale; PCS = Physical Component Summary .

length of time spent in 1 health state is multiplied by the utility value of this health state. Thus, cost-utility analysis presents cost per QALY gained by selecting one treatment over another. In spine care, where quality of life and patient satisfaction are the most important outcomes, this analysis is particularly important. Cost-utility ratios enable comparison of different interventions across numerous diseases, as a QALY has equal value irrespective of the nature of the alternative that delivers it.

Despite the importance of the information provided by cost-utility studies, there has been a lack of these types of studies in spine care. Brauer et al. ${ }^{9}$ systematically reviewed the orthopedic literature on cost-utility analyses and identified only 37 studies published between 1976 and 2001, with only $5(14 \%)$ pertaining to areas involving spine care. Dagenais et al. ${ }^{14}$ reviewed cost-utility analyses of interventions for low back pain published between 1998 and 2009 and identified only 15 studies. More recently, Kepler et al. ${ }^{26}$ identified 33 articles published between 1976 and 2010 on cost-utility analysis in spine care, with the majority of the studies published only recently. They identified only 4 articles addressing cost-utility of lumbar disc herniation surgery during this period. ${ }^{25,29,47,49}$ To the best of our knowledge, this study represents the first health economic analysis in spine care in Latin America.

To date, there has been no consensus regarding costeffectiveness thresholds for health interventions in Brazil. In fact, few Brazilian studies have been published on health economics, ${ }^{5,7,28,36,40}$ and none of them related to spine care in neurosurgery or orthopedics. Some countries have established that thresholds of what should be cost-effective: $\$ 50,000.00-\$ 100,000.00$ per QALY in the US, ${ }^{41}$ Can $\$ 20,000.00-\$ 40,000.00$ in Canada, ${ }^{23}$ and $£ 20,000.00-£ 30,000.00$ in the United Kingdom..$^{15}$ How-

TABLE 3. Costs of lumbar discectomy in the Brazilian Supplementary Health System

\begin{tabular}{lcrc}
\hline \multicolumn{1}{c}{ Description } & Mean Cost (R\$) & SD (R\$) & IQR (R\$) \\
\hline Surgical team & 1176.24 & 245.12 & $981.00-1430.00$ \\
\hline Anesthesiologist & 663.10 & 82.26 & $600.00-730.00$ \\
\hline Inpatient costs & 1587.37 & 295.41 & $1500.08-1733.00$ \\
\hline Total direct costs & 3426.72 & 394.17 & $3314.00-3660.08$ \\
\hline Indirect costs & 2027.67 & 2734.62 & $509.99-2138.04$ \\
\hline Total costs & 5454.40 & 2709.17 & $4002.00-5576.08$ \\
\hline
\end{tabular}

ever, economic differences within each country prevent these values to be transposed to and used in Brazil. ${ }^{7}$ According to the World Health Organization (WHO), threshold values of less than the gross domestic product (GDP) per capita are highly cost-effective, while between 1 and 3 times the GDP per capita is noted as cost-effective, and health interventions that cost more than 3 times the GDP per capita are considered not cost-effective (see http:// www.who.int/choice/costs/CER_levels/en/). In 2013, the Brazilian GDP per capita reached R $\$ 24,065.00$. However, it is important to note that thresholds established by the WHO and those used by developed countries were proposed under the public health or social perspective. In our study, using data from reimbursement by Brazilian health insurance and indirect costs associated with disability loss, the cost-utility ratio was $\mathrm{R} \$ 30,828.35$ per QALY gained with lumbar discectomy, thus demonstrating good cost-effectiveness of such surgical intervention in this developing country.

An important issue in health economics studies is the assumptions made in deriving QALYs from health outcomes. There is debate about the use of EQ-5D versus SF-6D utility values. ${ }^{42}$ We used the derived SF-6D values to calculate QALYs gained, which is a validated approach in cost-utility analyses. ${ }^{23}$ However, Obradovic et al. ${ }^{37}$ observed that EQ-5D might have a greater mean change from baseline to end point compared with SF-6D in patients with low-back pain or osteoarthritis knee pain ( 0.15 vs 0.05 , respectively), suggesting a higher construct validity and responsiveness in these patients. Similar findings were observed by Van den Hout et al. ${ }^{49}$ in their study of patients undergoing lumbar discectomy. In our study, we ascertained the cost-utility ratio in a 4-year perspective of gain using the SF-6D of 0.17 . The 4-year utility gain using EQ-5D observed in the Spine Patient Outcomes Research Trial (SPORT) was 0.34.48 These data suggest that the cost-utility ratio identified in our study may be underestimated by the use of SF-6D. In addition, our study did not evaluate the comparative effectiveness and costs of surgical versus conservative treatments in Brazil. Thus, we have not subtracted the savings associated with not continuing prolonged conservative treatment in cases in which medical management has already failed. In short, it is possible that LDH surgery may be even more costeffective in Brazil than our results would suggest.

Another important variable in cost-utility studies is 
the concept of the durability of benefits. In our study, we choose a 4-year horizon for health outcomes, assuming that the benefits of surgery remain 4 years postoperatively. This assumption is based on several studies using long-term follow-up of lumbar discectomy ${ }^{48}$ However, to reduce negative effects of this assumption, we have discounted the utilities by $3 \%$, effectively reducing the value of long-term gains. ${ }^{4}$

Regarding treatment of $\mathrm{LDH}$, the literature on the economics of surgery for discectomy have used different methodologies depending on various perspectives, such as that of the patient, payer, or society. Malter and Weinstein ${ }^{29}$ in their 1996 paper, studied the costs and quality of life associated with lumbar discectomy in LDH patients in the US using a Markov model. Hansson and Hansson, ${ }^{25}$ in a 2007 article, studied 92 Swedish patients who underwent surgical treatment for LDH and compared the total costs between the surgical and conservative treatment. Subsequently, van den Hout et al. ${ }^{49}$ performed a health care cost comparison between conservative care and early surgery in 141 patients from the Netherlands. Tosteson et al..$^{48}$ performed an "as-treated" analysis of cost-effectiveness in the US based on the pooled SPORT data obtained 2 and 4 years after surgery. In general, the reported cost utility of lumbar discectomy ranges from a cost saving to $\$ 79,000 /$ QALY gained compared with nonoperative treatment. ${ }^{25,26,29,47,49}$

In our study, the estimated cost-utility ratio was $\mathrm{R} \$ 30,828.35(\$ 12,845.14)$ per QALY gained. The sensitivity analysis showed a range of $\mathrm{R} \$ 25,690.29$ ( $\$ 10,714.28)$ to $\mathrm{R} \$ 38,535.44(\$ 16,056.43)$ per QALY gained. This cost per QALY gained with LDH surgery is lower than what was reported for SPORT ${ }^{48}$ or the cost-utility ratios reported by Malter and Weinstein, ${ }^{29}$ and van den Hout et al. ${ }^{49}$ for LDH surgery. Regarding other surgeries for spine disorders, the reported cost per QALY gained after transforaminal lumbar interbody fusion ranges between $\$ 42,854$ and $\$ 109,740 ; 1,1,38$ the corresponding range is $\$ 120,311.73-\$ 125,407$ for degenerative scoliosis, ${ }^{32,33,45}$ $\$ 33,700-\$ 115,600$ for lumbar stenosis, $, 2,38,46$ and $\$ 42,854$ $\$ 58,846$ for posterolateral lumbar fusion for degenerative conditions of the lumbar spine. ${ }^{1,2}$ With respect to nonspine studies, the cost per QALY gained that was observed in the present study can be compared with hip arthroplasty, for which the cost per QALY gained ranges between $\$ 29,139$ and $\$ 80,000 .{ }^{11}$ For total knee replacement, the cost per QALY gained has been reported as \$59,262. ${ }^{16}$ Infliximab, a cost-effective medication for rheumatoid arthritis, was found to have a cost per QALY gained of $\$ 30,500$ in a prospective randomized trial of 428 patients..$^{53}$ However, these data reflect costs in the North American health care system. The extent to which these data may be applied in other countries will depend on the actual costs of similar services within those specific countries.

This study evaluated costs of lumbar discectomy in the Brazilian supplementary health care system. Thus, this cost-utility ratio does not reflect the reality of the Brazilian publicly funded unified health care system, known in Brazil as the Sistema Único de Saúde (SUS). In fact, the majority of the Brazilian population is covered only by SUS. ${ }^{20}$ In SUS, the total reimbursement for direct hospital treatment of lumbar discectomy is $\mathrm{R} \$ 1720.27$. Considering only direct costs of lumbar discectomy for refractory lumbar disc herniation and using utility data from the reported database, the cost per QALY gained is $\mathrm{R} \$ 9722.99$ in the public health care system and $\mathrm{R} \$ 19,367.87$ in the supplementary Brazilian health care system. This low cost-utility ratio reflects the low reimbursement of SUS for LDH surgery in Brazil. Also, it must be noted that the utility gain for patients from public and private health care systems would not be similar. ${ }^{5}$ To date, there have been no published data on utility gain after LDH surgery in the Brazilian public health care system. Future studies are needed to address this issue and provide data on economic evaluation of LDH treatment in the Brazilian public health care system.

One limitation of our study was the relatively small sample size and consequently the low number of revision cases. In this cohort, 4 patients presented with recurrent disc herniation and only 1 underwent revision surgery. No patient with an incidental durotomy presented with postoperative cerebrospinal fluid leakage and needed revision. The total cost for the patient who needed revision surgery for recurrent disc herniation was R \$8468. Further Brazilian studies with larger samples should address the question of the economic impact of revision in lumbar discectomy. Also, as this was a single-center analysis, these results should be assessed for external validation in other Brazilian regions.

\section{Conclusions}

This study represents the first economic evaluation of spine care in Latin America. From a perspective of the Brazilian supplementary health care system, open discectomy for patients with $\mathrm{LDH}$ is a valuable treatment option with an appropriate cost-utility ratio and good clinical outcomes. Our findings provide a value measure of lumbar discectomy that can be compared with future cost-perQALY-gained analyses. This study should encourage additional cost-utility studies in Latin America.

\section{References}

1. Adogwa O, Parker SL, Davis BJ, Aaronson O, Devin C, Cheng JS, et al: Cost-effectiveness of transforaminal lumbar interbody fusion for Grade I degenerative spondylolisthesis. J Neurosurg Spine 15:138-143, 2011

2. Adogwa O, Parker SL, Shau DN, Mendenhall SK, Aaronson $\mathrm{O}$, Cheng JS, et al: Cost per quality-adjusted life year gained of revision neural decompression and instrumented fusion for same-level recurrent lumbar stenosis: defining the value of surgical intervention. J Neurosurg Spine 16:135-140, 2012

3. Alvin MD, Lubelski D, Abdullah KG, Whitmore RG, Benzel EC, Mroz TE: Cost-utility analysis of instrumented fusion versus decompression alone for Grade I L4-L5 spondylolisthesis at 1-year follow-up: a pilot study. J Spinal Disord Tech [epub ahead of print], 2014

4. Ament JD, Kim KD: Standardizing cost-utility analysis in neurosurgery. Neurosurg Focus 33(1):E4, 2012

5. Araújo CD, Veiga DF, Hochman BS, Abla LE, Oliveira AC, Novo NF, et al: Cost-utility of reduction mammaplasty assessed for the Brazilian public health system. Aesthet Surg J 34:1198-1204, 2014

6. Asch HL, Lewis PJ, Moreland DB, Egnatchik JG, Yu YJ, 
Clabeaux DE, et al: Prospective multiple outcomes study of outpatient lumbar microdiscectomy: should 75 to $80 \%$ success rates be the norm? J Neurosurg 96 (1 Suppl):34-44, 2002

7. Augustovski F, Iglesias C, Manca A, Drummond M, Rubinstein A, Martí SG: Barriers to generalizability of health economic evaluations in Latin America and the Caribbean region. Pharmacoeconomics 27:919-929, 2009

8. Botega NJ, Bio MR, Zomignani MA, Garcia C Jr, Pereira WA: [Mood disorders among inpatients in ambulatory and validation of the anxiety and depression scale HAD.] Rev Saude Publica 29:355-363, 1995 (Portuguese)

9. Brauer CA, Rosen AB, Olchanski NV, Neumann PJ: Costutility analyses in orthopaedic surgery. J Bone Joint Surg Am 87:1253-1259, 2005

10. Brazier J, Roberts J, Deverill M: The estimation of a preference-based measure of health from the SF-36. J Health Econ 21:271-292, 2002

11. Chang RW, Pellisier JM, Hazen GB: A cost-effectiveness analysis of total hip arthroplasty for osteoarthritis of the hip. JAMA 275:858-865, 1996

12. Ciconelli RM, Ferraz MB, Santos W, Meinão QM: [Translation into Portuguese and validation of the generic assessment of quality of life SF-36 (Brazil SF-36).] Rev Bras Reumatol 39:143-155, 1999 (Portuguese)

13. Cruz LN, Camey SA, Hoffmann JF, Rowen D, Brazier JE, Fleck MP, et al: Estimating the SF-6D value set for a population-based sample of Brazilians. Value Health 14 (5 Suppl 1):S108-S114, 2011

14. Dagenais S, Roffey DM, Wai EK, Haldeman S, Caro J: Can cost utility evaluations inform decision making about interventions for low back pain? Spine J 9:944-957, 2009

15. Devlin N, Parkin D: Does NICE have a cost-effectiveness threshold and what other factors influence its decisions? A binary choice analysis. Health Econ 13:437-452, 2004

16. Drewett RF, Minns RJ, Sibly TF: Measuring outcome of total knee replacement using quality of life indices. Ann R Coll Surg Engl 74:286-290, 1992

17. Ebeling U, Reichenberg W, Reulen HJ: Results of microsurgical lumbar discectomy. Review on 485 patients. Acta Neurochir (Wien) 81:45-52, 1986

18. Fairbank JC, Couper J, Davies JB, O'Brien JP: The Oswestry low back pain disability questionnaire. Physiotherapy 66:271-273, 1980

19. Fairbank JC, Pynsent PB: The Oswestry Disability Index. Spine (Phila Pa 1976) 25:2940-2952, 2000

20. Falavigna A, Canabarro CT, Medeiros GS: Health system and medical education in Brazil: history, principles, and organization. World Neurosurg 80:723-727, 2013

21. Falavigna A, Righesso O, Teles AR: Clinical and functional evaluation in preoperative period of degenerative disease spine surgery. Coluna/Columna 8:234-253, 2009

22. Falavigna A, Righesso O, Teles AR, Baseggio N, Velho MC, Ruschel LG, et al: Depression Subscale of the Hospital Anxiety and Depression Scale applied preoperatively in spinal surgery. Arq Neuropsiquiatr 70:352-356, 2012

23. Fehlings MG, Jha NK, Hewson SM, Massicotte EM, Kopjar $\mathrm{B}$, Kalsi-Ryan S: Is surgery for cervical spondylotic myelopathy cost-effective? A cost-utility analysis based on data from the AOSpine North America prospective CSM study. J Neurosurg Spine 17 (1 Suppl):89-93, 2012

24. Hanmer J: Predicting an SF-6D preference-based score using MCS and PCS scores from the SF-12 or SF-36. Value Health 12:958-966, 2009

25. Hansson E, Hansson T: The cost-utility of lumbar disc herniation surgery. Eur Spine J 16:329-337, 2007

26. Kepler CK, Wilkinson SM, Radcliff KE, Vaccaro AR, Anderson DG, Hilibrand AS, et al: Cost-utility analysis in spine care: a systematic review. Spine J 12:676-690, 2012
27. Korthals-de Bos I, van Tulder M, van Dieten H, Bouter L: Economic evaluations and randomized trials in spinal disorders: principles and methods. Spine (Phila Pa 1976) 29:442-448, 2004

28. Machado M, Iskedjian M, Einarson TR: Quality assessment of published health economic analyses from South America. Ann Pharmacother 40:943-949, 2006

29. Malter AD, Weinstein J: Cost-effectiveness of lumbar discectomy. Spine (Phila Pa 1976) 21 (24 Suppl):69S-74S, 1996

30. Maroon JC: Current concepts in minimally invasive discectomy. Neurosurgery 51 (5 Suppl):S137-S145, 2002

31. Martin BI, Deyo RA, Mirza SK, Turner JA, Comstock BA, Hollingworth W, et al: Expenditures and health status among adults with back and neck problems. JAMA 299:656-664, 2008

32. McCarthy I, Hostin R, O’Brien M, Saigal R, Ames CP: Health economic analysis of adult deformity surgery. Neurosurg Clin N Am 24:293-304, 2013

33. McCarthy I, O’Brien M, Ames C, Robinson C, Errico T, Polly DW Jr, et al: Incremental cost-effectiveness of adult spinal deformity surgery: observed quality-adjusted life years with surgery compared with predicted quality-adjusted life years without surgery. Neurosurg Focus 36(5):E3, 2014

34. McCulloch JA: Focus issue on lumbar disc herniation: macro- and microdiscectomy. Spine (Phila Pa 1976) 21 (24 Suppl):45S-56S, 1996

35. McLaughlin N, Ong MK, Tabbush V, Hagigi F, Martin NA: Contemporary health care economics: an overview. Neurosurg Focus 37(5):E2, 2014

36. Nita ME, Eliaschewitz FG, Ribeiro E, Asano E, Barbosa E, Takemoto M, et al: Cost-effectiveness and budget impact of saxagliptine as additional therapy to metformin for the treatment of diabetes mellitus type 2 in the Brazilian private health system. Rev Assoc Med Bras 58:294-301, 2012

37. Obradovic M, Lal A, Liedgens H: Validity and responsiveness of EuroQol-5 dimension (EQ-5D) versus Short Form-6 dimension (SF-6D) questionnaire in chronic pain. Health Qual Life Outcomes 11:110, 2013

38. Parker SL, Fulchiero EC, Davis BJ, Adogwa O, Aaronson OS, Cheng JS, et al: Cost-effectiveness of multilevel hemilaminectomy for lumbar stenosis-associated radiculopathy. Spine J 11:705-711, 2011

39. Räsänen P, Ohman J, Sintonen H, Ryynänen OP, Koivisto AM, Blom M, et al: Cost-utility analysis of routine neurosurgical spinal surgery. J Neurosurg Spine 5:204-209, 2006

40. Ribeiro RA, Stella SF, Zimerman LI, Pimentel M, Rohde LE, Polanczyk CA: Cost-effectiveness of implantable cardioverter defibrillators in Brazil in the public and private sectors. Arq Bras Cardiol 95:577-586, 2010

41. Rudmik L, Drummond M: Health economic evaluation: important principles and methodology. Laryngoscope 123:1341-1347, 2013

42. Sach TH, Barton GR, Jenkinson C, Doherty M, Avery AJ, Muir KR: Comparing cost-utility estimates: does the choice of EQ-5D or SF-6D matter? Med Care 47:889-894, 2009

43. Savettieri G, Salemi G, Rocca WA, Meneghini F, D'Arpa A, Morgante L, et al : Prevalence of lumbosacral radiculopathy in two Sicilian municipalities. Acta Neurol Scand 93:464469, 1996

44. Schizas C, Tsiridis E, Saksena J: Microendoscopic discectomy compared with standard microsurgical discectomy for treatment of uncontained or large contained disc herniations. Neurosurgery 57 (4 Suppl):357-360, 2005

45. Terran J, McHugh BJ, Fischer CR, Lonner B, Warren D, Glassman S, et al: Surgical treatment for adult spinal deformity: projected cost effectiveness at 5-year follow-up. Ochsner J 14:14-22, 2014

46. Tosteson AN, Lurie JD, Tosteson TD, Skinner JS, Herkowitz $\mathrm{H}$, Albert T, et al : Surgical treatment of spinal stenosis with 
and without degenerative spondylolisthesis: cost-effectiveness after 2 years. Ann Intern Med 149:845-853, 2008

47. Tosteson AN, Skinner JS, Tosteson TD, Lurie JD, Andersson GB, Berven S, et al: The cost effectiveness of surgical versus nonoperative treatment for lumbar disc herniation over two years: evidence from the Spine Patient Outcomes Research Trial (SPORT). Spine (Phila Pa 1976) 33:2108-2115, 2008

48. Tosteson AN, Tosteson TD, Lurie JD, Abdu W, Herkowitz H, Andersson G, et al: Comparative effectiveness evidence from the spine patient outcomes research trial: surgical versus nonoperative care for spinal stenosis, degenerative spondylolisthesis, and intervertebral disc herniation. Spine (Phila Pa 1976) 36:2061-2068, 2011

49. van den Hout WB, Peul WC, Koes BW, Brand R, Kievit J, Thomeer RT: Prolonged conservative care versus early surgery in patients with sciatica from lumbar disc herniation: cost utility analysis alongside a randomised controlled trial. BMJ 336:1351-1354, 2008

50. Vigatto R, Alexandre NM, Correa Filho HR: Development of a Brazilian Portuguese version of the Oswestry Disability Index: cross-cultural adaptation, reliability, and validity. Spine (Phila Pa 1976) 32:481-486, 2007

51. Ware JE Jr: SF-36 health survey update. Spine (Phila Pa 1976) 25:3130-3139, 2000

52. Weinstein JN, Lurie JD, Tosteson TD, Skinner JS, Hanscom B, Tosteson AN, et al: Surgical vs nonoperative treatment for lumbar disk herniation: the Spine Patient Outcomes Research Trial (SPORT) observational cohort. JAMA 296:2451-2459, 2006

53. Wong JB, Singh G, Kavanaugh A: Estimating the cost-effectiveness of 54 weeks of infliximab for rheumatoid arthritis.

Am J Med 113:400-408, 2002

\section{Disclosures}

The authors report receiving financial support from AOSpine Latin America. Dr. Riew reports being a board member and president of AOSpine International as well as being a member of the speakers' bureau of and receiving payments for lectures from AOSpine and NASS and from various universities for visiting professorships. He also reports direct stock ownership in Expanding Orthopedics, Amedica, Benvenue, Nexgen Spine, Osprey, Paradigm Spine, Spinal Kinetics, Spineology, Vertiflex, PSD, Medyssey.

\section{Author Contributions}

Conception and design: Falavigna, Scheverin, Teles, Gullo, Riew. Acquisition of data: Falavigna, Righesso. Analysis and interpretation of data: Falavigna, Scheverin, Teles, Gullo, Cheng, Riew. Drafting the article: Falavigna, Teles. Critically revising the article: Falavigna, Righesso, Teles, Gullo, Cheng, Riew. Reviewed submitted version of manuscript: Righesso, Teles, Cheng, Riew. Approved the final version of the manuscript on behalf of all authors: Falavigna. Statistical analysis: Teles. Study supervision: Scheverin.

\section{Supplemental Information Current Affiliations}

Dr. Riew: Department of Orthopedics, Columbia University, New York, NY.

\section{Correspondence}

Asdrubal Falavigna, University of Caxias do Sul, Leonilda Fasoli Zatti 201, Caxias do Sul 95050-250, Brazil. email: asdrubalmd@ gmail.com. 